This item was submitted to Loughborough's Research Repository by the author.

Items in Figshare are protected by copyright, with all rights reserved, unless otherwise indicated.

\title{
The lore and law of the playground
}

PLEASE CITE THE PUBLISHED VERSION

http://dx.doi.org/10.1080/21594937.2014.976030

\section{PUBLISHER}

(c) Taylor \& Francis

\section{VERSION}

AM (Accepted Manuscript)

\section{PUBLISHER STATEMENT}

This work is made available according to the conditions of the Creative Commons Attribution-NonCommercialNoDerivatives 4.0 International (CC BY-NC-ND 4.0) licence. Full details of this licence are available at: https://creativecommons.org/licenses/by-nc-nd/4.0/

\section{LICENCE}

CC BY-NC-ND 4.0

\section{REPOSITORY RECORD}

Butler, Carly W., and Amanda Bateman. 2019. "The Lore and Law of the Playground". figshare. https://hdl.handle.net/2134/17931. 
Bateman, A., \& Butler, C.W. (2014). The lore and law of the playground. International Journal of Play, 3(3), 235-250.

[Special Issue: Lifework and Legacy: Reviewing Iona and Peter Opie's Contribution to the Study of Play]

\title{
The Lore and Law of the Playground
}

\author{
Amanda Bateman (The University of Waikato) \\ Carly W. Butler (Loughborough University)
}

\begin{abstract}
The pioneering work of the Opies has been an inspiration to many people interested in children's play and games, academics and non-academics alike. Their books provide insightful details of how children interact and co-produce games through their rulemaking during everyday play, providing an awareness of the governance of social activities in the playground. In this article we explore the link between the work of the Opies and ethnomethodological and conversation analytic studies by identifying aspects of young children's games and rules that have been eloquently explored in both domains. The thoughtful move to make the recordings of Iona Opie's conversations with children about their games and associated rules available is fully utilised here, as excerpts are transcribed and analysed using conversation analysis. In so doing we demonstrate how conversation analysis can complement and extend the Opies' significant work on children's rule-making in play.
\end{abstract}

\section{Keywords}

Rule-making; children's games; ethnomethodology and conversation analysis; Iona Opie's audio recordings

\section{The Opies' exploration of children's rule-making in games}

The historic and pioneering work of the Opies has provided rich insight into the everyday lives of young children at play. Through their investigations into children's playground activities, the Opies have provided much detail about how children's games were co-produced throughout Britain in the latter half of the 20th century. The collective work of the Opies explores children's lore and rituals in their daily interactions, stimulating the interests of many academics interested in the historical significance of children's games (e.g. Bishop \& Curtis, 2001; Sutton-Smith, 1981). An enduring aspect of children's play noted by the Opies in games involving rules is that children are active participants in constructing and deconstructing their own rules of play. This interest in the governance of young children's social worlds is explored in a chapter dedicated to children's rule-making, entitled 'code of oral legislation' in their distinguished book The lore and language of schoolchildren (Opie \& Opie, 1959, pp. 121-153). The chapter outlines ways in which young children make rules, and shows how games are steeped in rituals, and verbal and non-verbal actions are employed to complement the affirmation of rules. 
The Opies provide many examples of how children's rules are asserted through rhyme. Even though the rhymes are documented as having regional variations, the messages in them were similar in that they declared rules that needed to be obeyed in fear of devastating consequences. Examples of such rules include swearing on the lives of loved ones or crossing one's heart and hoping to die. The Opies provide a comprehensive account of how the stated consequences of breaking a rule are accepted as truth and reality by the children in the playground:

He has very probably heard the tales his fellows tell of violent death instantly overtaking those who have dared to defy an oath; and it may well be that he believes these tales, however strange they sound to adult ears, for childhood is on nodding terms with the supernatural. (Opie \& Opie, 1959, p.122)

The observations of these children's rule-making demonstrate how, once a rule has been made, that child must commit to it or otherwise 'risks retribution' (p. 124).

Another way in which the Opies observed children to be using rules in their games was through their use of objects (Opie \& Opie, 1997). They found that children from all areas of Britain were enforcing rules about possession and ownership of items during their everyday play activities. For example, once a child gives an item to another child, the receiver is legally allowed to keep that item and never return it to the previous owner. When items are on offer, the quickest person to ask for the item is the legitimate person to receive it, drawing attention to the importance of the speediness of a response of the co-player in the form of a verbal action. When an item is lost, the rule of 'finding-keeping' is employed, such that the first person to find the missing object becomes the new owner of it. The Opies also discussed examples of objects being used to intimidate unpopular children, where children demanded to be given an object owned by an unpopular child or else suffer the consequences of physical violence. These rules worked to govern children's use of objects in their everyday play with one another and were delivered and reinforced through a variety of rhymes (Opie \& Opie, 1959; 1969; 1985; 1997; Opie, 1993).

The Opies' chapter on 'unpopular children' (1959, pp. 175-204) reveals a range of ways in which children jeer and exclude their peers for acting in ways that do not conform to the behaviour of other children. The classifications of children who were noted as unpopular included 'spoil-sports', 'fools', 'nosey parkers', 'cowards', 'crybabies' and 'crawlers', to name but a few. The 'unpopular children' were observably marked out as behaving in an unacceptable way by other children in the playground, and rhymes were made up and recited to explicate the rules of social conduct that had been broken. The consequences of being identified as 'unpopular' include being sent away, made to be quiet, or being intimidated or fought with. One way exclusion was managed was through 'sending a child to Coventry', documented through a child's writing of the scenario, 'When someone does something most of the class disagrees with, we send that person to Coventry which means we never speak to them' (Girl, 10, Birmingham, Opie \& Opie, 1959, p. 199). The act of exclusion through withholding verbal interaction is documented as a class decision, and all class members join together to make a rule about the nature and duration of punishment. Evidently, the behaviour that the children exhibited during their everyday play with 
each other is bound by rules of what was deemed acceptable or not by their peers, where engagement in unacceptable activities was punishable.

\section{An ethnomethodological approach to children's games and rules}

Ethnomethodology is a sociological approach that developed in the 1960s from the work of Harold Garfinkel (1967) and examines the methods people use to produce and make sense of the social world (i.e. their 'folk methods'). The ethnomethodological approach, and its subsequent development into conversation analysis (the systematic study of verbal and non-verbal practices in producing social action), takes an interest in interaction in everyday life. The focus on observing naturally occurring interaction has a natural resonance with the Opies' approach to capturing the 'lore and language' of children in the playground, and there is a shared interest in the ways in which talk and culture is used in the production and organisation of play.

One of the founders of conversation analysis, Harvey Sacks, had a particular interest in children's play and deeply admired the work of the Opies and what it revealed about children's cultures. Prior to his early death in 1975 at the age of 40, Sacks had been drafting a paper on children's play which appears as an appendix, entitled 'On some formal properties of children's games', amongst his published lectures (Sacks, 1992a, p. 489-507). In this paper, Sacks discusses the fundamental organisational features of children's games and how these are involved in socialisation and the coproduction of children's cultures. While an overview of Sacks's discussions of children's play is provided elsewhere (Hester \& Hester, forthcoming; also see Butler $\&$ Weatherall, 2006; Butler, 2008); here we focus on Sacks' work on the creation and application of rules in play.

Sacks proposed a set of properties that are general for children's games. Central among these were the notions that all games (with a name) have a 'category-set of players' and a 'category-set of game events', that is, each game involves a particular collection of members and a particular collection of things that need to happen as part of the game. Games are thus, in part, organized via an orientation to specifying and filling the category-sets of players and events, and managing the relationships between player and game events. Each player takes up membership in a particular category within the category-set of players, and there are certain activities associated with each category. If we take the example of a skipping game, we could say that the game requires a category-set composed of two turners and a jumper; a person turning the rope in a skipping game is a member of the category 'turner'. Certain activities are bound to that category, such as turning the rope, standing still and so on. Organizing a game like this requires that children sort (or 'map') themselves into the relevant categories, ensure all necessary categories are filled, that there is agreement on the category-set of game events, and that players engage in activities bound to their category membership (Butler, 2008; Butler \& Weatherall, 2006).

One of Sacks' (1992a, 1992b) key interests was the systematic ways through which social organization is co-produced in interaction, and he noticed how systematic turntaking sequences were evident in the early play of very young children. He documents how turn-taking is evident in young children's games, such as rolling balls to each other, or pushing each other on swings. The rules of these games were believed to be 
tied to systematic turn-taking and the co-production of social order, in that participating children deem sequential actions as either legal or illegal. Sacks emphasized the centrality of rule-making in shaping play activity:

It is obvious enough that a central property of game events is that for any given action the set whose members are mutually exclusive (legal-illegal) is of first-order relevance. The special importance of the fact lies in an affiliated one, and one that makes for the sharpness with which games provide a sense of the omni-presence of rightwrong considerations for actions: If an action in a game is attempted, and is done illegally, then the attempted action does not count at all. For purposes of being counted as an action, the thing is only countable if done, and if done correctly. An illegal action is invalid. (Sacks, 1992a, p. 500)

This recognition of the sequential and orderly ways in which rules are made as legally bound activities by one child and accepted as such by the recipient resonates with the work of the Opies. Both works discuss how actions of children in play relied on a common understanding of the rules specific to each game; where a rule was broken children oriented to the breaking of that rule as an illegal action.

Sacks (1992a) emphasised the accountability of breaking rules, suggesting that, when a person breaks a rule, they have made they are required to explain and justify breaking it. The sequential consequences of making a rule therefore determine such an action as having strategic and sequential considerations. Sacks discusses two sets of rules children orient to: Class 1 includes such rules as not poking fingers in a power socket, which has immediate consequences if broken; whereas Class 2 rules such as 'be good to your parents' have no immediate consequences for not being followed. Sacks suggests that children find it difficult to distinguish between these two classes of rules and so also find it difficult to judge the accountability of their actions; this is evident in the Opie's observations where the children believed the consequences of death as reality if they broke a rule.

In relation to the Opies' work on the social exclusion of 'unpopular children', Sacks (1992a) discussed the exclusion of children in relation to numbers of players in a game. Sacks suggests that one of the rules that children make about games are that there are a limited number of players where, 'any given game is properly nonplayable unless each category of the game's category-set has the proper number of incumbents' (Sacks, 1992a, p. 493). It was observed that children's games had specific category-sets of players, such as in basketball where each player has a role to play, and any additional children do not have a legal position in the game. Exclusion of children was therefore observed when a full set of members was evident in games. Recent research using conversation analysis to explore exclusion in children's interactions has shown that young children attend to the legal and illegal social actions of their peers in systematic ways that have implications for their membership within a play activity (e.g. Bateman, 2011; Butler, 2008; Butler \& Weatherall, 2006; Church, 2009; Cobb-Moore, Danby \& Farell, 2009; Evaldsson, 2004; GarciaSanchez, 2010; Goodwin, 1985; 1998; 2006; Griswold, 2007; Loyd, 2012; Melander, 2012; Svahn, 2012; Svahn \& Evaldsson, 2011). 
Through engaging in certain activities and behaving in a way that conforms to their peers, children demonstrate that they belong to a specific category of people.

Behaviors and actions that are understood to be carried out by members of a particular group are described as category-bound activities (CBA) (Sacks, 1992a; 1992b). Sacks noted that CBAs are one way in which the membership of a person within a specific group is made visible and recognizable by others. Furthermore, members of a group are held accountable for their actions, with members monitoring and regulating the behavior of one another such that the appropriate category-bound activities are carried out. The displayed CBA offers solidarity as group members act in a specific rulegoverned way (Sacks, 1992a). Members assert their application of a rule to the category to which they are a member, demonstrating their affiliation to that specific category and displaying the CBA that is tied to being a member. In games, then, each player category is associated with a set of activities that are bound to that category, which serve as a basis for identifying legal or illegal actions. More broadly, children's attention to the appropriate behaviors for one another is a crucial aspect of their social categorizations for one another (Evaldsson, 2007). Through asserting rules in their play, young children actively co-produce the social organization of the playground and determine which children are included and excluded, as is observable through rules tied to the use of environmental features such as playground huts (Bateman, 2011).

\section{Iona Opie's conversations with children about their games}

The following transcriptions are taken from Iona Opie's conversations with children made available through the British Library. ${ }^{1}$ Sections of the audio files have been transcribed below using a 'light' version of the conversation analysis transcription system (Jefferson, 2004). This aims to represent the features of talk that are relevant to participants in a conversation, such as silence within and between turns, stress and emphasis, and the volume, speed and pitch of talk (see Appendix). The analysis aims to reveal how playground rules and activities are described and explained by children from Coram Fields in their talk with Iona Opie. Through applying a conversation analytic approach to the data, we focus on the children's orientations to the organizational features of games, such as the CBA, that feature in the children's orientations to rules during play.

\section{Talk involving CBA in play and games}

This first transcript is taken from part one of a series of recordings of Iona's talk with children at Coram Fields in London. ${ }^{2}$ At the beginning of the interaction Iona initiates a topic about rubbish in the area with a noticing of the writing on the child's item of clothing 'litter stopper', which leads on to a description of a game.

\section{Observation 1: Crashing into dustbins}

\footnotetext{
${ }^{1}$ http://sounds.bl.uk/Oral-history/Opie-collection-of-children-s-games-and-songs-.

${ }^{2}$ British Library reference number C898/26, London, Coram Fields, 1974-07
} 
$06: 32$

(Observation 1 - Lines $01-48)$

01 Iona: What have you got written on your (front)

02 (litterstopper) that's a jolly good idea.

03 Iona: $\uparrow$ What do we do about litter in thi-

04 in Coram Fields. Does it- do they get

05 everybody to put it in baskets or what

06 do they do about it

$07 \mathrm{C}$ : No- no just the (clips) the: (caretakers)

08 just clean them out. Clean the things out like-

$09 \quad$ (1.5) Some [( )

10 Iona: [Is the litter very bad (here)?

$11 \mathrm{C}$ : Quite in:- mostly in the (.) pool.

$12 \mathrm{C}: \quad$ In the [swimming pool.

13 Iona: [(And it's got)

$14 \mathrm{C}: \quad$ Mostly in the [swimming pool

15 Iona: [In the paddling pool?

16 C: Yeah

17 Iona ( ) (why do they put it in the

18 paddling pools (I wonder)

$19 \quad(0.4)$

20 Iona: Huh! $\uparrow$ They don't- they- they don't throw pennies

21 and things in the paddling pool they throw

22 rubbish! Huh!

$23 \mathrm{C}$ : No usually people muck about with their

24 ( bikes ) cos they us- they usually have races and

25 they bang the dustbins ( ) the

26 dustbins topple over and usually the lunch

27 falls out.

28 Iona: What pe- what children have ra- races with the

29 rubbish bin?

$30 \mathrm{C}$ : Children have a race and so- when you can't stop

31 you just like dive off of the bi- just dive off

32 of the bike and let the bi(h)ke just run on its own

33 just go (.) let the bike run (.) dive off

$34 \quad(\quad)$

35 Iona: Wha- with the bike or with the dustbin

$36 \mathrm{C}$ : Um: with the scooter

37 Iona: With a scooter

$38 \mathrm{C}$ : Or a bike or anything. Anything that you can't

39 stop you just (dive in) and it knocks one of the

40 bins over and all the rubbish co(h)mes out.

41 Iona: $\mathrm{O}(\mathrm{h}) \mathrm{h}$ I se(h)e huh! So you've got all these

42 scooters and they're- they're- they belong

43 here don't they they've got Coram Fields

44 written on them.

$45 \mathrm{C}: \quad$ Yeah

46 Iona: Mm. I- $\mathrm{i}-$ is that a good thing to do?

$47 \mathrm{C}$ : Oh well [we enjoy it

48 Iona: [You- you enjoy it. 
The conversation about rubbish continues for several turns (lines 01-19) until Iona compares the activity of throwing pennies in the pool with throwing rubbish into it (line 20-22). By making this comparison, Iona (jokingly) treats the litter in the pool as a product of a play activity in which rubbish serves as a replacement for pennies. The child rejects this explanation for the litter as he offers an alternative play-based explanation, with a detailed description of the activities the children engage in, as they 'muck about' with bikes and have races that knock rubbish bins over (lines 23-27); the 'lunch falling out' of the bins as a result of this play serves as an explanation for the litter in the pool. Reflecting her primary interest in play, Iona focuses at this point on the description of the game as she seeks further clarification of the activity the children have been revealed as engaging in (lines 28-29).

Focusing on lines 30-40, the child produces a description of the play that frames it as something following a general pattern of actions. While starting off by repeating Iona's beginning 'children have a race', he then shifts into use of the generic 'you' (Sacks, 1992), which here refers to 'anybody' and marks a shift into describing a formula, or standard practice, for carrying out these races. When 'you' can't stop, presumably through going at such speed in the race, the children 'dive off'. The rather dramatic choice of descriptor 'dive' as part of this generalised account of action treats this as an activity bound to the category of 'racer'. You then 'let' the bike, or scooter, or 'anything you can't stop' (line 38-39) run off on its own. It is not particularly clear whether the diving, bin-knocking and rubbish falling out is part of the game itself; yet, the generic and formulaic presentation of this series of events involved in the races offers up a set of actions that seem bound to members of the racers. It is not that this has happened once, or that one child does this, but that 'not being able to stop', 'diving off' and 'knocking bins over' are all category-bound activities within the racing game. The rich description of the play illustrates how children produce their games with a focus on the boundedness and repeatability of actions; what serves as an explanation for litter in the pool is a product of the activities category bound to the racing game. Through giving such a detailed insight into the play, the child reveals the rules embedded in the purposeful activities and the importance of engaging in such specific activities in order to be a member of that game.

The following extract demonstrates similar formulations of a game in which children are divided into different categories of players, with different category-bound activities.

Observation 2: Chasing games

(Ob 1 - lines $82-142)$

82 Iona: Do- do you play any chasing:- (0.2) hiding: (.)

$83 \mathrm{C}$ : yeah

$84 \quad$ (.)

85 Iona: kind of games?

$86 \quad(1.3)$

87 Iona: Wha- [what-

$88 \mathrm{C}: \quad$ [Hide and see:: [games 
89 C2: $\quad$ [(Hide and stop)

$90 \mathrm{C1}$ : Hide and see: games an' (.) (----) (1.5)

91 run outs:, (0.7) few other games.

$92 \quad(1.0)$

93 Iona: Do you know- do you know the game that- that

94 starts off with um (4.6) do you know a game

95 that- that starts off with drawing a snake

96 on somebody's back.

$97 \quad(2.0)$

98 C: Um yeah

$99 \quad(0.5)$

100 Iona: Do you?

$101(\mathrm{C}): \quad(--)$

$102 \quad(0.4)$

103 Iona: Y'do.=Wha- what are the words that you use

104 for that.

$105 \quad(0.4)$

$106 \mathrm{C}: \quad$ (just tag)

$107 \mathrm{C} 2$ :(you get tagged)

108 ((unclear/quiet))

109 C3: (... what's the thing) (when) and then, when you

110 come [(say that) (----------)

111 (hide behind the tree,) and the ones who don't

112 get (tagged)(behind) (the tree).

$113 \mathrm{C}$ ? And if he can get the tree:, $(\quad)(\quad)$

114 (to hide behind)(----------------------)

115 Iona: (Oh I see)

$116 \mathrm{C}: \quad(\quad)$

117 Iona: What do you cal- what do you call that game?

$118 \mathrm{C}$ : Tig tag.

119 Iona Tig tag?

120

121

( ) (I like this)

122 Iona: $\uparrow$ So what does- wha- wha- what (would one of you)

123 draw (of the) snake? Anything?

$124 \quad(0.4)$

$125 \mathrm{C}: \quad(-------------)$

$126 \mathrm{C} 2: \quad[(-------)$

127 Iona [They draw any[thing?

$128 \mathrm{C}$ : [Initials,

$129 \mathrm{C}: \quad(\quad)$

130 Iona: And then the person who's hiding his eyes

131 has to guess who it was, (1.1) and then- (0.6)

132 that person: (.) has to: be the chaser, (0.7)

133 everybody else runs off behind a tree,

134 (0.6) and they will- (0.5) [(are we-)

135 Child [(If they dra:w

136 a tree;

$137 \quad(0.5)$

138 Child: On (the back,)

$139 \quad(0.5)$

140 Child: (See if they can guess it?)

$141 \quad(0.7)$

142 Iona: $\uparrow$ Oh they draw a tre:e on his back. 
Following a brief interlude of talk about people stealing the scooters, Iona brings the topic of conversation back to play and games. Iona enquires about two general categories of games: 'chasing' and 'hiding' (line 82). She refers to these via mention of the activities bound to these games, as 'hiding' or 'chasing' are part of the category-set of game events that players are involved in. The child identifies and names particular games within this broad category as he suggests the game 'hide and see' (or seek), run outs and 'a few other games' (lines 88 \& 90-91). Following this, the link between a game and the activities involved in doing that game are further attended to as a description of a game is given (line 93-96) and the game is recognised in the offering of a name (line $106 \&$ 107). Iona responds to the child's description by enquiring about the name of the game (lines 117), which could be tied to her interest in the many forms of the game 'tag' that the Opies have documented (Opie \& Opie, 1993).

At line 122, Iona asks for more information about how the game is played, in what seems to be a request for clarification about what is drawn on the child's back. She then goes on to propose the sequence of game events (lines 130-134). Her description of what happens is produced through a series of linking up or 'mapping' players to activities in the game; for instance, the child who is 'hiding his eyes' (the player) has to 'guess who it was' (the activity). The process of guessing then identifies which child is mapped into the category of 'chaser,' while 'everybody else' (line 133) is presumably mapped as a hider, for which the relevant activity is 'run behind a tree'. By breaking the play down into this sequence of category mapping and activities, Iona highlights how the order and structure of children's games are produced. Her clear familiarity with games of this type, and the ways in which they are organised, allows her to formulate the co-production of the game in a way that recognises and values the organisation of children's culture in and through games.

In the following extract, Iona explores how mapping to the category of 'chaser' is managed in other versions of the games.

\section{Observation 3: Activities for starting a game}

(Ob 2 lines $154-227)$

154 Iona: Huh. How do you decide who's going to be: the

155 one who chases o:r

$156 \mathrm{C}$ : Oh yeah we have a game and we just say first

157 three, and if there's- um if there's like um-

158 (we'll show) one two (no this way)

159 yeah you go and there's three people hold

160 on we'll do it one two three yeah

$161 \mathrm{C}$ : one two three ((together $))$

$162 \mathrm{C}: \quad$ (Fish eyes) ((19:05))

$163 \mathrm{C}$ : And then go - if there's somebody like that he goes

164

$165 \mathrm{C}: \quad[$ put this down )

166 Iona: Ah so you go one two three with your fis:ts,

$167 \mathrm{C}$ : Like this

168 Iona: $\mathrm{Hm}_{i}$

$169 \mathrm{C}$ : No like that 
170 Iona: Oh you clinch- an' you sort of hook your-

171 hook your fingers onto each others I see and

172 you'd go one two three and then you break

Several lines are omitted where the children explain the various hand positions to Iona, and what they represent.

199 Iona: And it's a question of who wins over

200 who is it? $\mathrm{Um}=$

$201 \mathrm{C}$ : Yeah cos you've [got-

202 Iona: [Supposing you had- you

203 had crane and he had cup and saucer which

204 would win.

$205 \mathrm{C}$ : I would. Because I [(---)

206 Iona: [Because you'd grabbed

207 the cup and saucer out. Oh I see.

$208 \mathrm{C}$ : If there's three people you go >one two

209 three $<$ and the odd one out.$h$ is not i:t.=

210 and you have to round in the last three

211 you go one two three and if there's any-

212 if you- (yeah that's fine) and then somebody

213 gets out and then the last three, whoever's

214 the odd one is it o::r one two three and there's

215 only two people left so you: (0.5) with the

216 two you go one (.) two (.) and then you have

217 (it like that) and go- you can't do anything

218 you go one two >one two three< ()

$219>$ one two three $<$ and (both playing) > one two

$220 \quad$ three $<$ hold on what's cu- cup paper (choose)

$221 \quad$ cup paper and like that and then you have

222 best of three it's called .h and then- if you-

223 if you get three, oh if you have three like

224 that then three like that, [and then they=

225 Iona: $\quad$ OOh I see

$226 \mathrm{C}$ : =then the one who had the three is not it

227 and the other one is it.

As noted by Sacks (1992), mapping often occurs at the beginning of games, when children need to organise who is going to do what. While conversation analysis research on pretend play has shown how children manage this through talk, the Opies outlined a number of ways in which the 'starting' of a game was achieved (1969: pages 17 - 57). In this example, Iona explores this by asking the children about the methods used in mapping players into categories in the game of chase, and particularly how they decide who is going to 'chase'. The children explain that this is done through a game (line 156), and they go on to describe and demonstrate a hand game (lines 155-165) that sounds like a Rock Paper Scissors variant. In their description the children outline the actions and sequences that are deemed acceptable and legal in determining the roles of players. Iona clarifies the activities through her formulation of the children's talk and what sounds like her embodied attempts to take part (lines $166 \&$ 170-172), attending to the importance of performing the actions precisely in order for them to 'count' in this mapping game. 
In the transcript that has been omitted, there are several conversational exchanges between Iona and the children as they discuss what each hand shape represents (such as a clawed hand symbolizing a crane) before Iona returns the conversation to the rules of selection regarding membership in the start of games (lines 199-200). The issue at hand is what counts as 'winning'. Iona tests the rules tied to the activities through providing a hypothetical situation and asking who would win in this case (lines 202-204). The child responds by identifying the winner and referring to the rule of action that would be deemed as correct by the members of the game. Following this, the child then offers an elaborate explanation of the rules of the game. This explanation highlights the rules tied to acceptable activities within the game and how game actions are linked to membership in particular categories; thus the actions of the children result in the social organization of who is 'it' and who is 'out' (lines 208227). Through exploring the CBAs made available in this conversation between Iona and the children, this interaction reveals how children engage in a systematic series of actions that make them visible members of a category of players, and how engaging in specific CBAs enforces rules of social organization when starting a game.

\section{Observation 4: Activities for exiting a game}

A game serves as a sense-making device which structures and organises how players (and observers) understand and interpret actions. When children are engaged in a game, all of their activities can potentially be treated as being bound to their membership in a player category, and they can be held accountable for not engaging in activities bound to their player category (Bateman, 2011; Butler, 2008). This becomes a practical matter for children when they want to step outside a game momentarily, as they need to demonstrate that they are 'not playing' so that they are exempt from having their activities treated as part of the game. Iona explores how children manage this situation in the following conversation:

(Ob 2 lines 70-122)

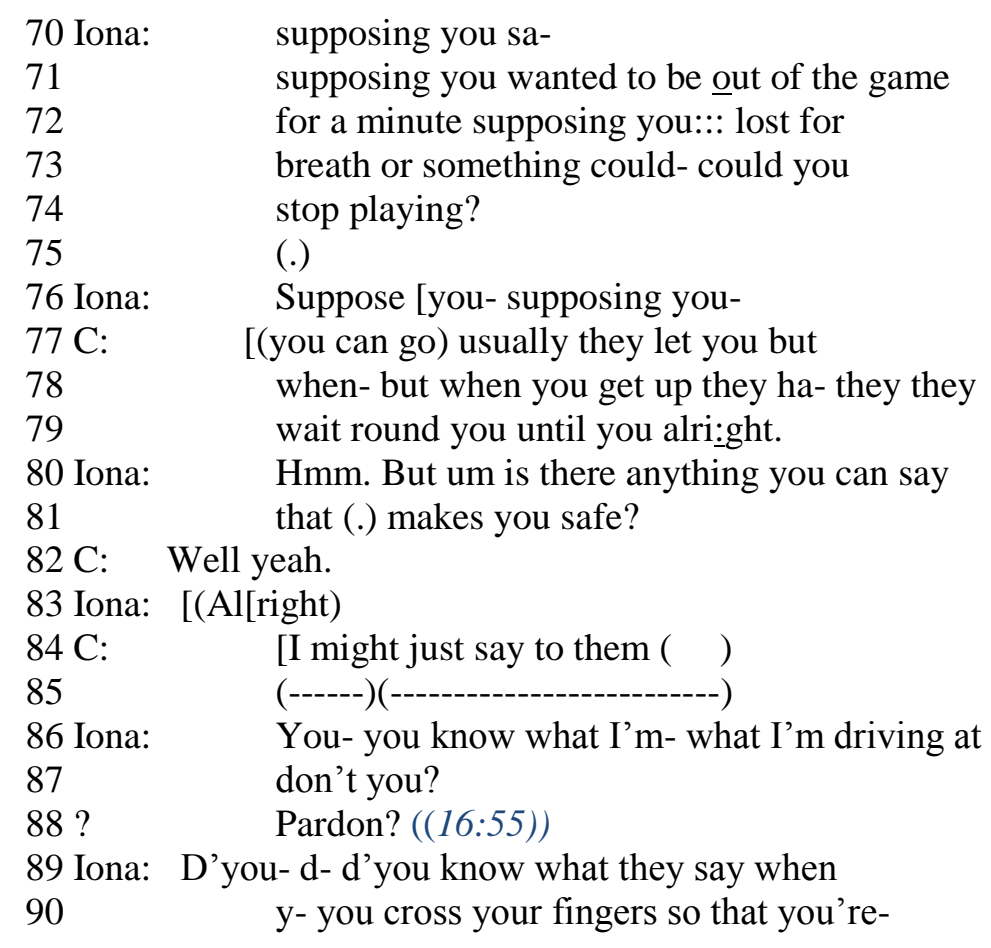




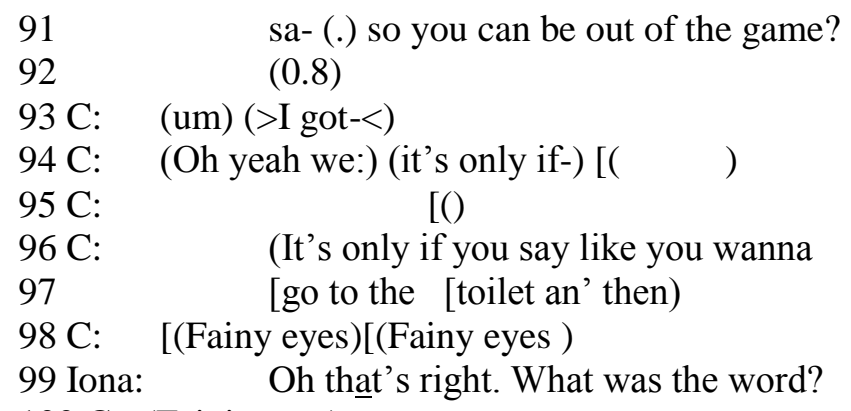

$100 \mathrm{C}$ : (Fainie eyes)

101 Iona: Fainie eyes? An- And if you wanna go- you

102 Say that when you want to go to the toi:let

103 do you?

$104 \mathrm{C}$ : Anything urgent.

$105 \quad$ (0.4)

106 Iona: Anything urgent. [Oh I: see

$107 \mathrm{C}$ : $\quad$ [ $\uparrow$ If you- if you did

$108 \mathrm{C}:$ An' if-

$109 \mathrm{C}$ : If you couldn't [(play) ( )

$110 \mathrm{C}$ : [If somebody chea:ts u:m

111 and you don't tell 'em you're not playing

112 your go fainie eyes (0.2) and then you

113 tell 'em).

$114 \quad(0.7)$

115 Iona: Oh I see.=So:-

116 C: Say um: like um: you: make a new ru:le, for

117 the game so: (you ) ( ) (then you say it)

118 (fayn-) (fainie eye:s) and then you go

119 up to them and they can say what do you like

120 even if they're i:t.

$121 \quad$ Iona: M:m.

122 C: They can- touch you but you're not it.

123 Iona: That's right

This series of conversational exchanges begins by Iona questioning how children go about exiting a game of tig-tag momentarily, exploring whether the 'ending' of a child's part in a game may be produced through a systematic series of actions or whether a child could simply 'stop' playing (lines 70-76). She asks this through a hypothetical example in which a player may want to 'be out of the game for a minute' because they were out of breath (line 72). What Iona is fishing for is an example of a 'truce term' which is described as 'perhaps the most important word in the schoolchild's vocabulary' (Opie \& Opie, 1959, p. 162), one that gives the child some respite from an ongoing game.

The way Iona formulates the question demonstrates her recognition of the particular structures of participation in play, whereby 'stopping playing' (lines 73-74) is something one needs some sort of permission to do. The child responds by explaining that 'usually they let you' but implies that they wait around you while you recover so that they can tag you the moment you are okay. So, in this case, permission to stop does not equate to being 'safe to stop'. However, this account does not provide an example of a truce term so Iona pursues this by offering an example - a method of crossing one's fingers (which was the usual method across England and Wales). This 
then triggers the phrase 'fainy eyes' (line 100), ${ }^{3}$ which appears to be a variant of a common truce term, 'faynights' or 'fains'. The children's use of the phrase 'fainie eyes' to exit a game is acknowledged by the Opies (Opie \& Opie, 1959), where variations are discussed in relation to the spelling and articulation of the phrase, but a general understanding for the use of the phrase suggests the call for 'respite' (p. 151).

Iona picks up on the children's responses, checking that she has the information correct, and the children confirm her understanding and then return to saying 'fainie eyes' and confirming the legal use of this phrase as a way of exiting a game (110113). The rules tied to the use of the phrase during the ongoing activity of a game are subsequently revealed, indicating its importance to the children as it allows a temporary suspension of roles where, even if you are 'it' in a game of chase, the phrase will allow you to approach another player (lines 116-120). In this sense, the phrase allows a child's activities not to be seen as being bound to their player category. The game of chase involves the roles of 'chaser', a member of the game who will chase after other members with the intention of catching them, and 'chased', members of the game who run away from the chaser to avoid being caught (Opie \& Opie, 1959), presenting the children in partitioning categories of players (Sacks, 1992a). However, through the use of the phrase 'fainie eyes' the members temporarily and legally suspend the game, allowing the 'chaser' to approach the chased without them running away. It suspends the relevance and application of player categories and their associated activities.

Observation 6: Disputes around girls' activities

(Ob 2 - lines 128 - 153)

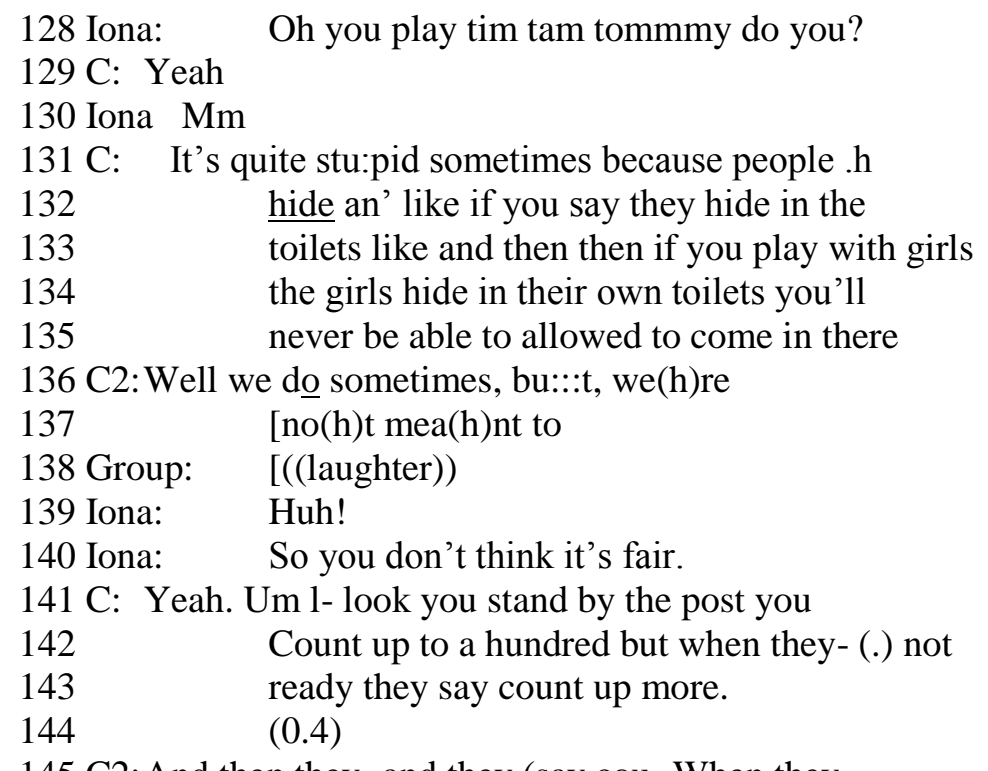

145 C2:And then they- and they (say cou- When they

\footnotetext{
${ }^{3}$ This seems to be some version of what the Opies (1977[1959], p151) identify as 'fainies', 'fainites', 'faynights', or 'fains I' - all terms for 'obtaining respite'. The transcription spells the term in line with these other versions, while trying to capture the way it is said. While there certainly seems to be three syllables (fay-nee-eyes), this doesn't match any of the forms recorded in the 1959 publication.
} 
$146 \quad$ keep on finding places when

147 they- say- okay ready; And then they go

148 (and) goes $\uparrow$ we're not ready $\uparrow$. And:- so:- (0.2)

149 And says are you rea(h)dy and (they) go

150 .h y'no- we're not ready count up to a

152 hundred again.

$153 \quad(0.4)$

$154 \mathrm{C}$ : And then they really ready just waiting there.

The conversation between Iona and the children regarding their games continues when a new game, Tim Tam Tommy, is mentioned and Iona picks up on it (line 128). The children subsequently make reference to the rules of the game that the players must abide by and how the girl members do not abide by the rules. As with the prior talk explored in this article, the children and Iona initially attend to the name of the game before giving an elaborate explanation regarding the accepted and legal activities in the co-production of the game (lines 131-135). One set of players in this game is the 'hiders', to which 'hiding' is a necessary category-bound activity. However, some hiding activity is treated as problematic, as girls can hide in the girls' toilet where boys are not legally allowed access (lines 134-135). In this instance, the girls are able to make use of their membership as girls to support their activities as hiders, and stymie the activities of the male 'seeker,' whose gender-based categorybound restrictions prevent him from effectively seeking (most of the time!). While this is characterised as 'stupid' (line 131) and unfair, it is not treated as outside of the rules; it still 'counts' even if it makes the play impossible.

There are further accusations of the girls engaging in unfair activities in relation to the part of the game where the seeker has to count while the hiders hide. The children suggest that the girls conduct this aspect of the game unfairly too, as they ask for more time than is legally warranted (lines 140-154).

\section{Extending the work of the Opies}

The Opies' work offers a rich insight into the rules, routines and rituals that children used to structure and organise their play. The extent and the complexity of children's social worlds, and the numerous rules and practices that shape and govern their play and interaction, are made visible throughout the Opies' documentation. While many laws of childhood are delivered and transmitted through rhyme and song, they are acknowledged as very 'serious' in the sense of establishing and moulding the bounds of legal and illegal actions of acceptable and non-acceptable behaviour by the Opies. Iona Opie's conversations with the children reveal the scripted nature of these rules, and the children's production of the rules as mapping what is legal or illegal in play; the sense in which children's worlds are political is made clear in these records of their lore. The audio recordings help bring to life the sense in which, as the Opies describe, the lore of the playground is something firmly within children's expertise.

The recordings can reveal a great deal about how children describe their play and games as formulaic, rule-bound, and monitored. Ethnomethodological work involving conversation analysis offers a method for observing and understanding when and how children's lore is produced and re-produced, affording an insight into folklore-in- 
action. This detailed approach to revealing the sequences involved in the coproduction of everyday activities, such as children's play, perfectly complements the type of recording and cataloguing that the Opies engaged in. As such, we can learn a lot about the structure and organization of play, and more of the formal properties of play that Sacks suggested are evident in all games. This article has highlighted the way in which one aspect of the Opies' work on children's games regarding rulemaking and 'codes of oral legislation' can be further explored through the use of an ethnomethodological approach and conversation analysis, but we envisage that much more work can be done.

\section{Appendix}

\section{CA transcription conventions}

The conversation analysis symbols used to transcribe the data are adapted from Jefferson's conventions described in Sacks, Schegloff and Jefferson (1974).

[ the beginning of an overlap

] the end of an overlap

$=\quad$ the equals sign at the end of one utterance and the beginning of the next utterance marks the latching of speech between the speakers. 
When used in-between words it marks the latching of the words spoken in an utterance with no break.

the time of a pause in seconds

$:$ lengthening of the prior sound. More or less colons are used to represent the longer or shorter lengthening.

$\uparrow \quad$ a rising intonation in speech

$\downarrow \quad$ a falling intonation in speech

Underscore marks an emphasis placed on the underscored sound

Bold words which are underscored and bold indicate heavy emphasis or shouting

${ }^{\circ}$ degree $\operatorname{sign}^{\circ} \quad$ either side of a word indicates that it is spoken in a quiet, soft tone

(brackets) utterance could not be deciphered

((brackets $)$ double brackets with words in italics indicate unspoken actions

\$dollar\$ Dollar signs indicate the talk was in a smile voice

${ }^{\star} \mathrm{creaky}^{\star} \quad$ Asterisks indicate the talk was in creaky voice

>arrows $<\quad$ utterance spoken quickly

\section{References}

Bateman, A. (2011). Huts and heartache: The affordance of playground huts for legal debate. Journal of Pragmatics, 43, 3111-3121.

Bishop, J. C., \& Curtis, M. (2001). Play today in the primary school playground: Life, learning and creativity. Buckingham: Oxford University Press.

Butler, C. W. (2008). Talk and social interaction in the playground. Aldershot: Ashgate.

Butler, C., \& Weatherall, A. (2006). 'No, we're not playing families': Membership categorisation in children's play. Research on Language and Social Interaction, 39, 441-470. 
Church, A. (2009). Preference organisation and peer disputes: How young children resolve conflict. Aldershot: Ashgate.

Cobb-Moore, C., Danby, S. \& Farrell, A. (2009). Young children as rule makers. Journal of Pragmatics, 41, 1477-1492.

Evaldsson, A-C. (2004). Shifting moral stances: The situational relevance of rules in same sex and cross sex games. Research on Language and Social Interaction, 37, 331-363.

Evaldsson, A-C. (2007). Accounting for friendship: Moral ordering and category membership in preadolescent girls' relational talk. Research on Language and Social Interaction, 40, 377-404.

Garcia-Sanchez, I. (2010). Serious games: Code-switching and gendered identities in Moroccan immigrant girls' pretend play. Pragmatics, 20, 523-555.

Goodwin, M. H. (1985). The serious side of jump rope: Conversational practices and social organization in the frame of play. Journal of American Folklore, 98, 315-330.

Goodwin, M. H. (1998). Games of stance: Conflict and footing in hopscotch. In S. Hoyle \& C. T. Adger (Eds.), Kids' talk: Strategic language use in later childhood (pp. 23-46). New York: Oxford University Press.

Goodwin, M. H. (2006). The hidden life of girls: Games of stance, status, and exclusion. Oxford: Blackwell.

Griswold, O. (2007). Achieving authority: Discursive practices in Russian girls' pretend play. Research on Language and Social Interaction, 40: 291-320.

Hester, S and Hester, S. (forthcoming). Children's play and games: Contributions from ethnomethodology and conversation analysis. Aldershot: Ashgate.

Jefferson, G. (2004). Glossary of transcript symbols with an introduction. In G. H. Lerner (Ed.), Conversation analysis: Studies from the first generation (pp. 13-31). Amsterdam: John Benjamins.

Loyd, H. (2012). The logic of conflict: Practices of social control among inner city Neapolitan girls. In S. Danby and M. Theobald (Eds.), Disputes in everyday life: Social and moral orders of children and young people (pp. 325-353). Bingley: Emerald Group.

Melander, H. (2012). Knowing how to play the game of jump rope: Participation and stancetaking in a material environment. Journal of Pragmatics, 44: 232-248.

Opie, I., \& Opie, P. (1959). The lore and language of schoolchildren. Oxford: Oxford University Press. 
Opie, I., \& Opie, P. (1969). Children's games in street and playground. Oxford: Clarendon Press.

Opie, I., \& Opie, P. (1985). The singing game. Oxford: Oxford University Press.

Opie, I., \& Opie, P. (1993). The people in the playground. Oxford: Oxford University Press.

Opie, I., \& Opie, P. (1997). Children's games with things. Oxford: Oxford University Press.

Sacks, H. (1992a). Lectures on conversation (Vol. I). Oxford: Blackwell.

Sacks, H. (1992b). Lectures on conversation (Vol. II). Oxford: Blackwell.

Sacks, H., Schegloff, E. A and Jefferson, G. (1974) A Simplest Systematics for the Organisation of Turn-Taking for Conversation, Language, Volume 50, pp $696-735$.

Sutton-Smith, B. (1981). A history of children's play: New Zealand Playground, 1840-1950. University of Pennsylvania Press: Pennsylvania.

Svahn, J. (2012). The everyday practice of school bullying: Children's participation in peer group activities and school-based anti-bullying initiatives. Uppsala Studies in Education, no. 129. Uppsala: Department of Education, Uppsala University.

Svahn, J., \& Evaldsson, A. (2011). You could just ignore me: Situating peer exclusion within the contingencies of girls' everyday interactional practices, Childhood, 18: $155-171$.

\section{Notes on contributors}

Amanda Bateman is a senior lecturer in early childhood education and is a member of the Early Years Research Centre at the University of Waikato, New Zealand. She has published in the area of early childhood peer interactions and teacher-child interactions using conversation analysis and membership categorisation analysis. Amanda has lead two funded projects, and an international collaborative project investigating the impact of the earthquakes on the children living in Christchurch, New Zealand.

Dr Carly Butler is a senior lecturer in social psychology in the Department of Social Sciences at Loughborough University. Her research involves using ethnomethodological and conversation analysis to examine naturally occurring social interaction, with a focus on children's play and interaction, family interaction and helpline interaction. She has published widely in these areas, including her book Talk 
Lore \& law of the playground - Author Version - 2014

and Social Interaction in the Playground (2008). 